\title{
Theoretical study of the gas-phase structures of sodiated and cesiated leucine and isoleucine: zwitterionic structure disfavored in kinetic method experiments
}

\begin{abstract}
Marko Rožman
The most stable charge-solvated (CS) and zwitterionic (ZW) structures of sodiated and cesiated leucine and isoleucine were studied by density functional theory methods. According to the Boltzmann distribution in gas phase, both forms of LeuNa ${ }^{+}$and IleNa ${ }^{+}$exist, but in LeuCs ${ }^{+}$and IleCs ${ }^{+}$, the $\mathrm{ZW}$ forms are dominant. Results for the sodiated compounds are consistent with the relationship found between decrease in relative stability of CS versus ZW form and aliphatic amino acid side chain length. The observed degeneracy in energy for IleNa ${ }^{+}$conformers is at odds with kinetic method results. Additional calculations showed that kinetic method structural determinations for $\mathrm{IleNa}^{+}$do not reflect relative order of populations in the lowest energy conformers. Since complexation of cationized amino acids into ionbound dimers disfavors $\mathrm{ZW}$ structure by $\sim 8 \mathrm{k} \mathrm{J} \mathrm{mol}^{-1}$, it is suggested that for energy close conformers of sodium-cationized amino acids, the kinetic method may not be reliable for structural determinations.
\end{abstract}

KEYWORDS: leucine; isoleucine; alkali metals; gas-phase structure; density functional theory; kinetic method

\section{INTRODUCTION}

Gas-phase alkali metal-cationized amino acids and the stability of their gas-phase zwitterionic (ZW) structures are intensively studied. Present theoretical calculations show that gas-phase alkali metal-cationized amino acids ${ }^{1-11}$ with the exception of arginine $e^{3,12}$ and proline ${ }^{2,13}$ are more stable in the charge-solvated (CS) form. However, looking at relative stabilities of $\mathrm{ZW}$ and CS forms (expressed by their energy difference, $\left.\Delta_{Z W-C S}\right)$ of sodium-cationized aliphatic amino acids $\left(\mathrm{GlyNa}^{+}-\Delta_{\mathrm{ZW}-\mathrm{CS}}=11.7 \mathrm{~kJ} \mathrm{~mol}^{-1}\right.$, $\mathrm{AlaNa}^{+}-\Delta_{\mathrm{ZW}-\mathrm{CS}}=5.0 \mathrm{~kJ} \mathrm{~mol}^{-1}, \mathrm{ValNa}^{+}-\Delta_{\mathrm{ZW}-\mathrm{CS}}=$ $\left.3.8 \mathrm{~kJ} \mathrm{~mol}^{-1}\right),{ }^{4,7,10}$ a decrease in energy differences which follows the aliphatic side chain enlargement can be observed. This trend gives a reason for this study, i.e. to theoretically analyze the CS and ZW structures of $\mathrm{IleNa}^{+}$and $\mathrm{LeuNa}^{+}$ and their relative stabilities.

Mass spectrometrical determinations of gas-phase structures of alkali metal-cationized amino acids mainly result from ion mobility, ${ }^{14}$ gas-phase H/D exchange ${ }^{15}$ and kinetic method ${ }^{16}$ experiments. However, in most cases, these results are not conclusive. Ion mobility is frequently limited because
CS and ZW structures can have very similar cross sections. ${ }^{4}$ The gas-phase exchange experiments have shown that regardless of the deuterium reagent, only $\mathrm{ZW}$ forms of sodium-cationized amino acids are probed. ${ }^{11,17,18}$ Study of $H / D$ exchange mechanism suggested that prior to $H / D$ exchange reaction, there is a quasi-energy-free transition from CS to ZW structure in the amino acid. ${ }^{18}$ As yet, kinetic method experiments produced the majority of results, which were also in agreement with theoretical predictions..$^{5,19}$

Wyttenbach et al. ${ }^{4}$ reported an interesting correlation between the stability of the gas-phase ZW/CS structures of alkali ion-cationized amino acids and their proton affinities (PA). On the basis of this correlation, it was suggested that sodium-cationized amino acids with proton affinity above $\sim 910 \mathrm{~kJ} \mathrm{~mol}^{-1}$ predominately have $\mathrm{ZW}$ structures. But, in the suggested correlation, the possibility of the extra coordination site for sodium cation provided by the functional side chain group was ignored, and it was later demonstrated that this prediction is at odds with theoretical and kinetic method results. ${ }^{5,19}$

The ZW conformations of sodium-cationized amino acids have a proton attached to the most basic site, and if probed in a kinetic method experiment, linear correlation between sodium ion affinities $\left(\Delta H_{\mathrm{Na}}\right)$ and PA is expected. ${ }^{20}$ Kish et al. ${ }^{20}$ analyzed 17 amino acids by the kinetic method and found poor correlation $\left(R^{2}=0.601\right)$ between corresponding affinities. It was concluded that poor correlation suggests 


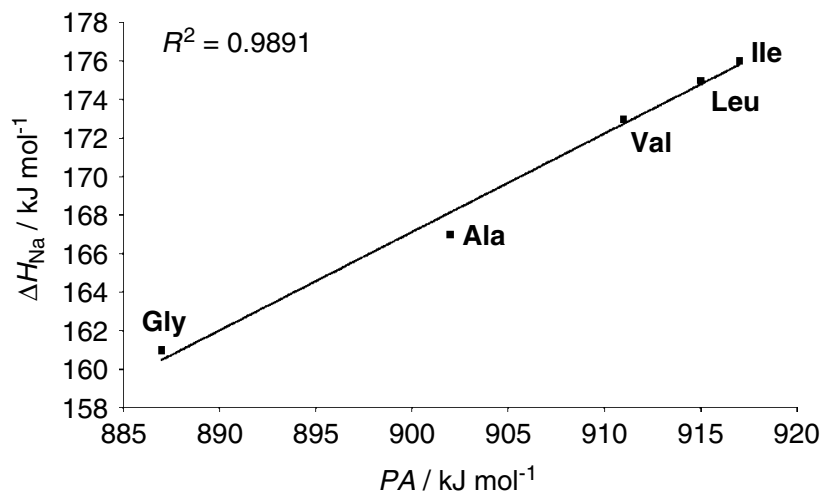

Figure 1. Correlation plot of the proton affinities versus sodium ion affinities of aliphatic amino acids. Dots represent experimental data from Ref. 20 and full line represents their least-square fit.

CS structure of sodium-cationized amino acids. But, if we correlate only proton and sodium ion affinities of aliphatic amino acids (with no extra coordination site), a good correlation $\left(R^{2}=0.989\right)$ can be found (Fig. 1). Furthermore, if the ZW stability limit ${ }^{4}$ (amino acids with proton affinity above $910 \mathrm{~kJ} \mathrm{~mol}^{-1}$ ) is applied, this could mean that in the gas phase, the presence of $\mathrm{ZW}$ forms of $\mathrm{LeuNa}^{+}$and IleNa ${ }^{+}$ should not be neglected.

The above finding provided additional motivation for this work in which structures of IleNa ${ }^{+}$and $\mathrm{LeuNa}^{+}$were analyzed by means of the density functional theory (DFT). Additionally, in order to test kinetic method results, sodiumbound dimers of Ile were theoretically analyzed and their relative stabilities were compared with those of the monomers.

\section{COMPUTATIONAL METHODS}

DFT calculations were performed using the GAUSSIAN 03 program package ${ }^{21}$ on the computer cluster at the 'Ruder Bošković' Institute. Initial search of minima on potential energy surface (PES) was performed by using B3LYP functional ${ }^{22,23}$ with $6-31 \mathrm{G}^{*}$ basis set. The obtained geometries were additionally reoptimized at the B3LYP/6-311++ $\mathrm{G}^{* *}$ level. The cesiated structures were studied at the B3LYP/LanL2DZ level. Harmonic vibrational analyses have been performed in order to characterize each stationary point as a minimum on the PES; these results were also used to obtain zero point vibrational energy (ZPVE). The basis set superposition error (BSSE) was not calculated because it was assumed that relative energies of the studied structures are independent of BSSE.

\section{RESULTS AND DISCUSSION}

In order to identify the most stable conformers of CS and ZW sodium-cationized Ile and Leu, we used the strategy of a similar conformer. In this approach, the starting structures were built from the most stable conformations of the studied alkali metal-cationized amino acids (glycine, alanine and valine). ${ }^{4,6,7,10,18}$ Special care was taken for modeling a coordination site of the cation, which involves either the lone pair electrons of carbonyl oxygens in the $\mathrm{ZW}$ or those of carbonyl oxygen and the amine nitrogen in the CS structure. Aliphatic side chains in both forms (CS and ZW) of cationized amino acids were placed in different positions with steric strain taken into consideration. These geometries were then optimized at the B3LYP/6-31G* level and then reoptimized at the B3LYP/6-311++ $\mathrm{G}^{* *}$ level to obtain final energy and relative stabilities. The lowest-energy gas-phase CS and ZW structures of LeuNa ${ }^{+}$and $\mathrm{IleNa}^{+}$are shown in Fig. 2. The corresponding B3LYP/6 $-311++\mathrm{G}^{* *}$ energies, ZPVE-corrected energies $\left(E_{\mathrm{ZPVE}}\right)$ and relative stabilities of conformers are listed in Table 1.

For both amino acids, the CS structure in which $\mathrm{Na}^{+}$is coordinated by carbonyl and amino group lone pair electrons appears to be energetically more stable. In the less stable ZW form, the positive charges of sodium cation and protonated amino group are separated by the negative charge of the carboxylic group. The energy differences between CS and ZW structures are very small (practically degenerate), and from the presented data, it is obvious that the relative stability decreased when compared with glycine, alanine and valine (vide supra). It was suggested ${ }^{19}$ that one reason for stabilizing the salt bridge $(\mathrm{ZW})$ structure is the linearity of the +-+ charges (H-O-Na angle). However, all aliphatic amino acids have pretty much the same $\mathrm{H}-\mathrm{O}-\mathrm{Na}$ angle $\left(\sim 180^{\circ}\right)$. So, additional stabilization of $\mathrm{ZW}$ forms may result from $-\mathrm{NH}_{3}{ }^{+}$ group stabilization by aliphatic (electron donor) side chains in agreement with the link between decrease in relative energies and length of aliphatic side chain (vide supra). From values in Table 1 and according to the Boltzmann distribution at $300 \mathrm{~K}$, one should expect the existence of CS and ZW forms of studied sodium-cationized amino acids in the gas phase. On the other hand, experimental results ${ }^{19}$ predict the existence of only CS forms of both sodium-cationized amino acids. In these experiments, to compare the relative stability of alkali metal $\left(\mathrm{M}^{+}\right)$- cationized amino acid conformations, J. M. Talley et al. ${ }^{19}$ used the kinetic method.

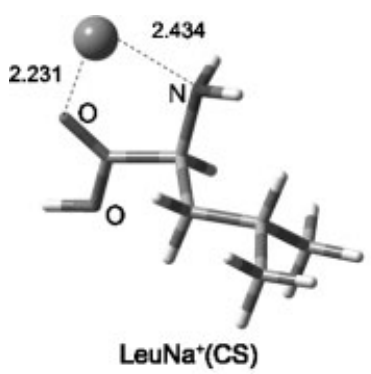

LeuNa+(CS)

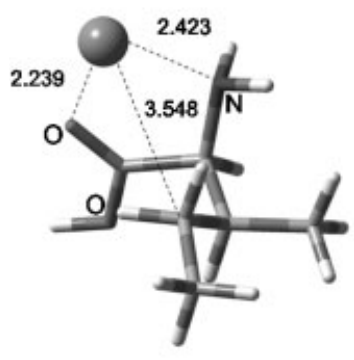

lleNa+(CS)

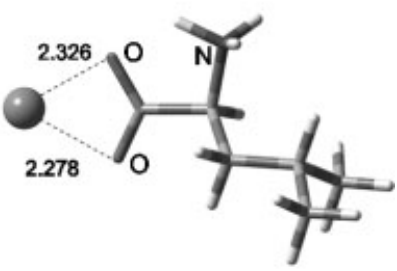

LeuNa+(ZW)

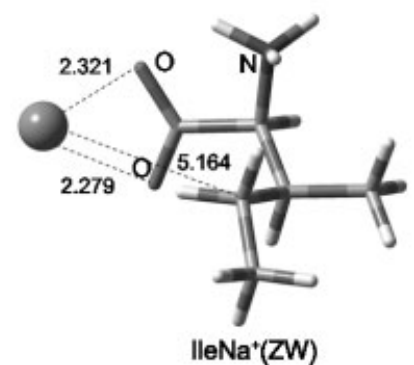

Figure 2. The most stable conformers of $\mathrm{LeuNa}^{+}$and IleNa ${ }^{+}$in a CS and $Z W$ form at B3LYP/6-311++ $G^{\star *}$. 
Table 1. Energies, ZPVE-corrected energies (both in $E_{\mathrm{h}}$ ) and relative stabilities (in $\mathrm{kJ} \mathrm{mol}^{-1}$ ) of LeuNa ${ }^{+}$and IleNa ${ }^{+}$conformers computed at the B3LYP/6-311++ ${ }^{\star *}$ level

\begin{tabular}{lccccccc}
\hline \multirow{2}{*}{$\begin{array}{l}\text { Amino acid } \\
\text { Conformer }\end{array}$} & \multicolumn{3}{c}{ LeuNa $^{+}$} & & \multicolumn{3}{c}{$\mathrm{IleNa}^{+}$} \\
\cline { 2 - 4 } \cline { 7 - 8 } & $\mathrm{CS}$ & $\mathrm{ZW}$ & $\Delta_{\text {ZW }-\mathrm{CS}}$ & $\mathrm{CS}$ & $\mathrm{ZW}$ & $\Delta_{\text {ZW-CS }}$ \\
\hline$E$ & -603.986528 & -603.985421 & 2.9 & & -603.98455 & -603.984429 & 0.3 \\
$E_{\text {ZPVE }}$ & -603.791762 & -603.790789 & 2.6 & & -603.78969 & -603.789449 & 0.6 \\
\hline
\end{tabular}

The kinetic method is based on dissociation of an ionbound dimeric cluster. If the gas-phase amino acid is in the CS form, its methyl ester will bind $\mathrm{M}^{+}$more strongly as a consequence of electron-donating properties of the methyl group. ${ }^{19}$ Dissociation of this dimer will yield more abundant population of amino acid methyl ester- $\mathrm{M}^{+}$. A more abundant population of amino acid $-\mathrm{M}^{+}$will be formed by dissociation of the [amino acid(ZW)-M-amino acid methyl ester $]^{+}$dimer. The $\mathrm{ZW}$ form of amino acid $-\mathrm{M}^{+}$binds $\mathrm{M}^{+}$more strongly because of ionic interactions between $\mathrm{COO}^{-}$and $\mathrm{M}^{+}$.

Still, the mere fact that more ions of methyl ester are formed does not necessarily mean that gas-phase CS amino acid $-\mathrm{M}^{+}$was more stable and/or most abundant. In the kinetic method, there is a dissociation of a FAB-, MALDI- or ESI-formed $\mathrm{M}^{+}$-bound dimer, and one should take care to see whether the most stable dimer probed by kinetic method is actually formed from the most stable $\mathrm{M}^{+}$cationized amino acids and their methyl esters. Previous energy comparisons of dimers versus monomers reported disfavor of ZW structure relative to CS upon complexation but no reversal of energy ordering in case of lithiated glycine. ${ }^{1}$ Similar comparison for lithiated proline showed energy reversal and the ZW structure was disfavored. ${ }^{19}$ To test this possibility for the energy-equivalent gas-phase conformers of IleNa ${ }^{+}$, calculations for Ile-Na-IleOMe ${ }^{+}$were carried out.

Sodium-bound clusters of $\mathrm{Ile}(\mathrm{CS})-\mathrm{Na}-\mathrm{IleOMe}{ }^{+}$and $\mathrm{Ile}(\mathrm{ZW})-\mathrm{Na}-\mathrm{IleOMe}{ }^{+}$were formed from the most stable conformations of corresponding amino acids and their methyl esters. Those clusters were then optimized at the B3LYP $/ 6-311++G^{* *}$ level to obtain the final energies and relative stabilities. The most stable conformations are shown in Fig. 3, while corresponding B3LYP/6-311++ $\mathrm{G}^{* *}$ energies, ZPVE-corrected energies $\left(E_{\mathrm{ZPVE}}\right)$ and relative stabilities of clusters $\left(\Delta_{Z W-C S}\right)$ are listed in Table 2.

In the most stable sodium-bound cluster of Ile and IleOMe, the Ile is in the CS form. The energy difference between Ile(CS)-Na-IleOMe ${ }^{+}$and Ile(ZW)-Na-IleOMe ${ }^{+}$ is $8.1 \mathrm{~kJ} \mathrm{~mol}^{-1}$. Additional stabilization of the $\mathrm{Ile}(\mathrm{CS})-\mathrm{Na}-$ $\mathrm{IleOMe}^{+}$dimer is probably the result of better coordination/solvation of sodium cation with aliphatic (electrondonating) side chains (Fig. 3). In the Ile(CS)-Na-IleOMe ${ }^{+}$ cluster, the sodium cation is coordinated by two aliphatic side chains, while in $\mathrm{Ile}(\mathrm{ZW})-\mathrm{Na}-\mathrm{IleOMe}{ }^{+}$because of the ZW nature of interaction, sodium is coordinated by only one side chain.

The expected population ratio of those two dimers based on Boltzmann distribution at $300 \mathrm{~K}$ is $99.6: 0.4$ in favor of $\mathrm{Ile}(\mathrm{CS})-\mathrm{Na}-\mathrm{IleOMe}{ }^{+}$. On the other hand, the population ratio of gas-phase CS and ZW forms of $\mathrm{IleNa}^{+}$is 57.8 to 42.2 ,

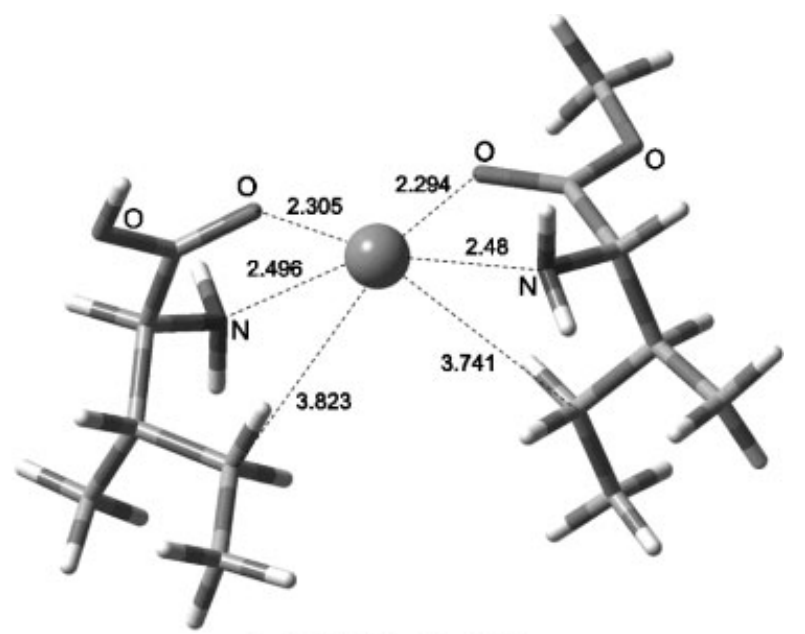

Ile(CS)-Na-IleOMe+

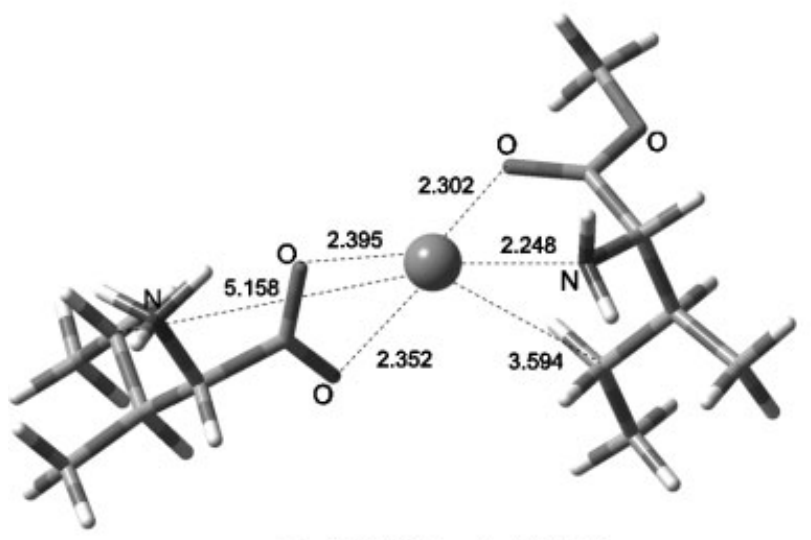

$\mathrm{Ile}(\mathrm{ZW})-\mathrm{Na}-\mathrm{lleOMe} \mathrm{M}^{+}$

Figure 3. Dimers Ile(CS)-Na-lleOMe ${ }^{+}$and Ile(ZW)-Na-IleOMe ${ }^{+}$ obtained by the B3LYP/6 $-311++\mathrm{G}^{\star \star}$ optimization.

Table 2. The B3LYP/6-311++ $\mathrm{G}^{\star \star}$ energies, ZPVE-corrected energies (in $E_{\mathrm{h}}$ ) and relative stabilities (in $\mathrm{kJ} \mathrm{mol}^{-1}$ ) of $\mathrm{Ile}(\mathrm{CS})-\mathrm{Na}-\mathrm{IleOMe}{ }^{+}$and Ile(ZW)-Na-lleOMe ${ }^{+}$dimers

\begin{tabular}{lccc}
\hline Dimer & Ile(CS)-Na-IleOMe ${ }^{+}$ & Ile(ZW)-Na-IleOMe & $\Delta_{\text {ZW-CS }}$ \\
\hline$E$ & -1085.17264 & -1085.169555 & 8.1 \\
$E_{\text {ZPVE }}$ & -1084.755863 & -1084.752879 & 7.8 \\
\hline
\end{tabular}

respectively. Although, because of the nature of the theoretical treatment (error of the method), the calculated Boltzmann distribution should be considered only as approximate, the following trend is evident: population ratios of the CS and $\mathrm{ZW}$ forms of IleNa ${ }^{+}$based on the dissociation of most stable Ile-Na-IleOMe ${ }^{+}$dimers do not represent actual population 
Table 3. Interatomic distances (in $\AA$ ) in the $\mathrm{LeuCs}^{+}$, IleCs ${ }^{+}$, Ile(CS)-Cs-lleOMe ${ }^{+}$and Ile(ZW)-Cs-lleOMe ${ }^{+}$calculated on the B3LYP/LanL2DZ level of theory

\begin{tabular}{|c|c|c|c|c|c|c|c|c|}
\hline \multirow{2}{*}{$\frac{\text { Bond }}{\text { Cs-N }}$} & \multirow{2}{*}{$\frac{\mathrm{LeuCs}^{+}(\mathrm{CS})}{3.43}$} & \multirow{2}{*}{$\frac{\text { LeuCs }^{+}(\mathrm{ZW})}{-}$} & \multirow{2}{*}{$\frac{\mathrm{IleCs}^{+}(\mathrm{CS})}{3.381}$} & \multirow{2}{*}{$\frac{\mathrm{IleCs}^{+}(\mathrm{ZW})}{-}$} & \multicolumn{2}{|c|}{ Ile(CS)-Cs-IleOMe ${ }^{+}$} & \multicolumn{2}{|c|}{ Ile(ZW)-Cs-IleOMe } \\
\hline & & & & & 3.475 & 3.441 & - & 3.453 \\
\hline Cs-O (N side) & 2.987 & 3.156 & 3.009 & 3.146 & 3.08 & 3.058 & 3.229 & 3.081 \\
\hline $\mathrm{Cs}-\mathrm{O}$ & - & 3.078 & - & 3.09 & - & - & 3.153 & - \\
\hline Cs-C ( $\beta$-C ethyl group) & - & - & 4.266 & 5.844 & 4.369 & 4.336 & 5.93 & 4.226 \\
\hline
\end{tabular}

Table 4. Energies, ZPVE-corrected energies (both in $E_{\mathrm{h}}$ ) and relative energies (in kJ mol${ }^{-1}$ ) of LeuNa+ and lleNa+ conformers computed at the B3LYP/LanL2DZ level

\begin{tabular}{|c|c|c|c|c|c|c|}
\hline \multirow{2}{*}{$\begin{array}{l}\text { Amino acid } \\
\text { Conformer }\end{array}$} & \multicolumn{3}{|c|}{$\mathrm{LeuCs}^{+}$} & \multicolumn{3}{|c|}{$\mathrm{IleCs}^{+}$} \\
\hline & CS & $\mathrm{ZW}$ & $\overline{\Delta_{\mathrm{ZW}-\mathrm{CS}}}$ & CS & $\mathrm{ZW}$ & $\overline{\Delta_{\mathrm{ZW}-\mathrm{CS}}}$ \\
\hline$E$ & -461.385707 & -461.395198 & -24.9 & -461.383545 & -461.394439 & -28.6 \\
\hline$E_{\mathrm{ZPVE}}$ & -461.19128 & -461.200837 & -25.1 & -461.189487 & -461.199784 & -27 \\
\hline
\end{tabular}

Table 5. The B3LYP/LanL2DZ energies, ZPVE-corrected energies (in $E_{\mathrm{h}}$ ) and relative energies (in $\mathrm{kJ} \mathrm{mol}^{-1}$ ) of $\mathrm{Ile}(\mathrm{CS})-\mathrm{Cs}-\mathrm{IleOMe} \mathrm{H}^{+}$and Ile(ZW)-Cs-lleOMe ${ }^{+}$dimers

\begin{tabular}{lccc}
\hline Dimer & Ile(CS)-Cs-IleOMe & Ile(ZW)-Cs-IleOMe & $\Delta_{\text {ZW-CS }}$ \\
\hline$E$ & -942.327405 & -942.335825 & -22.1 \\
$E_{\text {ZPVE }}$ & -941.910582 & -941.919376 & -23.1 \\
\hline
\end{tabular}

ratios of the CS and $\mathrm{ZW}$ forms of IleNa ${ }^{+}$. In kinetic method experiments, Ile(CS)-Na-IleOMe ${ }^{+}$dimers will be probed, and their dissociation will yield a more abundant population of the IleOMeNa+ and, thereby, leads to the conclusion that the CS form of IleNa ${ }^{+}$is the dominant one.

DFT calculation showed here that kinetic method experiments for IleNa ${ }^{+}$do not reflect relative populations of the lowest energy conformers. For $\mathrm{IleCs}^{+}$, the kinetic method gives the $\mathrm{ZW}$ form as the more stable. ${ }^{19}$ To further test the kinetic method results and reliability of DFT calculations, complexation of Ile with $\mathrm{Cs}^{+}$was investigated. Conformations of IleCs ${ }^{+}$and Ile-Cs-IleOMe ${ }^{+}$were built in a such way that in the most stable conformations of IleNa ${ }^{+}$and Ile-NaIleOMe ${ }^{+}$, the sodium was replaced by the cesium cation. Structures were then optimized at the B3LYP/LanL2DZ level where the final energetic and relative stabilities were obtained (Tables 3, 4 and 5).

On the basis of the presented data, one can presume that in both, the stable conformation of $\mathrm{IleCs}^{+}$and the more stable Ile-Cs-IleOMe ${ }^{+}$dimer, Ile is in the $\mathrm{ZW}$ form. Dissociation of that dimer will yield the $\mathrm{ZW}$ form of $\mathrm{IleCs}^{+}$ as the stable one in agreement with predictions of being the more stable form of monomer. The theoretical result is also in accordance with the kinetic method experimental result. ${ }^{19}$ The relative energies again showed the $\mathrm{IleCs}^{+} \mathrm{ZW}$ form to be disfavored but without reversal in energy ordering because of great energy differences between the CS and ZW forms. Additional stabilization of the CS dimer is probably a result of a better coordination/solvation of cesium cation by two aliphatic side chains (instead of one in $\mathrm{ZW}$ dimer). According to the previous ${ }^{1,19}$ and present 'tests' of kinetic method reliability, it seems that complexation of cationized amino acids into ion-bound dimers favors the CS structure by $\sim 8 \mathrm{~kJ} \mathrm{~mol}^{-1}$.

\section{CONCLUSIONS}

DFT study of $\mathrm{LeuNa}^{+}$and $\mathrm{IleNa}^{+}$indicated a relationship between decrease in energy difference of ZW and CS forms and aliphatic side chain length. Results for IleNa ${ }^{+}$showed energy degeneracy of CS and ZW conformers, which is consistent with predictions based on correlation between sodium ion and proton affinities and ZW stability limit. On the other hand, the energy degeneracy for CS and ZW conformers of IleNa ${ }^{+}$is not consistent with kinetic method results. Additional calculations on the relative stability of $\mathrm{Na}^{+}$-bound dimers of Ile and IleOMe showed discrepancy between relative stabilities of naturally occurring gas-phase $\mathrm{CS}$ and $\mathrm{ZW}$ forms and those produced by dissociation of Ile-Na-IleOMe ${ }^{+}$.

Further study of $\mathrm{LeuCs}^{+}$and IleCs ${ }^{+}$showed $\mathrm{ZW}$ forms to be the more stable ones in agreement with relative stabilities of conformers obtained from simulated dissociation of $\mathrm{Cs}^{+}$bound dimers of Ile and IleOMe. These results are in agreement with kinetic method experiments.

Finally, the most interesting conclusions are that complexation of cationized amino acids into ion-bound dimers disfavors $\mathrm{ZW}$ structure by $\sim 8 \mathrm{~kJ} \mathrm{~mol}^{-1}$ and that for conformers of sodium-cationized amino acids which are close in energy the kinetic method may not be reliable for structural determinations.

\section{Acknowledgements}

Helpful discussions with Dr Dunja Srzić and Dr Leo Klasinc are gratefully acknowledged. The Ministry of Science, Education and Sports of Republic of Croatia and Croatian Academy of Sciences and Arts Foundation supported this work.

\section{REFERENCES}

1. Hoyau S, Ohanessian G. Interaction of alkali metal cations $\left(\mathrm{Li}^{+}-\mathrm{Cs}^{+}\right)$with glycine in the gas phase: A theoretical study. Chem. Eur. J. 1998; 4: 1561. 
2. Hoyau S, Norrman K, McMahon TB, Ohanessian G. A quantitative basis for a scale of $\mathrm{Na}^{+}$affinities of organic and small biological molecules in the gas phase. J. Am. Chem. Soc. 1999; 121: 8864.

3. Wyttenbach T, Witt M, Bowers MT. On the question of salt bridges of cationized amino acids in the gas phase: glycine and arginine. Int. J. Mass Spectrom. 1999; 182/183: 243.

4. Wyttenbach T, Witt M, Bowers MT. On the stability of amino acid zwitterions in the gas phase: the influence of derivatization, proton affinity and alkali ion addition. J. Am. Chem. Soc. 2000; 122: 3458.

5. Ryzov V, Dunbar RC, Cerda B, Wesdemiotis C. Cation- $\pi$ effects in the complexation of $\mathrm{Na}^{+}$and $\mathrm{K}^{+}$with Phe, Tyr and trp in the gas phase. J. Am. Soc. Mass Spectrom. 2000; 11: 1037.

6. Marino T, Russo N, Toscano M. Gas-phase metal ion $\left(\mathrm{Li}^{+}, \mathrm{Na}^{+}, \mathrm{Cu}^{+}\right)$affinities of glycine and alanine. J. Inorg. Biochem. 2000; 79: 179.

7. Marino T, Russo N, Toscano M, A Density Functional Study. Potential energy surfaces for the gas-phase interaction between $\alpha$-alanine and alkali metal ions $\left(\mathrm{Li}^{+}, \mathrm{Na}^{+}, \mathrm{K}^{+}\right)$. Inorg. Chem. 2001; 40: 6439 .

8. Dunbar RC. Complexation of $\mathrm{Na}^{+}$and $\mathrm{K}^{+}$to aromatic amino acids: A density functional computational study of cation- $\pi$ interactions. J. Phys. Chem. A 2000; 104: 8067.

9. Gapeev A, Dunbar RC. Na ${ }^{+}$affinities of gas-phase amino acids by ligand exchange equilibrium. Int. J. Mass Spectrom. 2003; 228: 825.

10. Lemoff AS, Bush MF, Williams ER. Binding energies of water to sodiated valine and structural isomers in the gas phase: the effect of proton affinity on zwitterion stability. J. Am. Chem. Soc. 2003; 125: 13576.

11. Rožman M. Gas phase structure of the sodiated amino acids probed by H/D exchange reactions. Croat. Chem. Acta 2005; 78: 185.

12. Jockusch RA, Price WD, Williams ER. Hydration of valine-cation complexes in the gas phase: on the number of water molecules necessary to form a zwitterion. J. Phys. Chem. A 1999; 103: 9266.

13. Marino $\mathrm{T}$, Russo $\mathrm{N}$, Toscano $\mathrm{M}$. Interaction of $\mathrm{Li}^{+}, \mathrm{Na}^{+}$and $\mathrm{K}^{+}$ with proline amino acid. Complexation modes, potential energy profiles and metal ion affinities. J. Phys. Chem. B 2003; 107: 2588.

14. Wyttenbach T, Bowers MT. Gas-phase conformations: The ion mobility/ion chromatography method. Top. Curr. Chem. 2003; 225: 207.
15. Green MK, Lebrilla CB. Ion-molecule reactions as probes of gasphase structures of peptides and proteins. Mass Spectrom. Rev. 1997; 16: 53.

16. Cooks RG, Patrick JS, Kotiaho T, McLuckey SA. Thermochemical determinations by the kinetic method. Mass Spectrom. Rev. 1994; 13: 287.

17. Cox HA, Julian RR, Lee SW, Beauchamp JL. Gas-phase H/D exchange of sodiated glycine oligomers with $\mathrm{ND}_{3}$ : exchange kinetics do not reflect parent ion structures. J. Am. Chem. Soc. 2004; 126: 6485

18. Rožman M, Bertoša B, Klasinc L, Srzić D. Gas phase H/D exchange of sodiated amino acids: why do we see zwitterions? J. Am. Soc. Mass Spectrom. accepted for publication.

19. Talley JM, Cerda BA, Ohanessian G, Wesdemiotis C. Alkali metal ion binding to amino acids versus their methyl esters: affinity trends and structural changes in the gas phase. Chem. Eur. J. 2002; 8: 1377.

20. Kish MM, Ohanessian G, Wesdemiotis $\mathrm{C}$. The $\mathrm{Na}^{+}$affinities of $\alpha$-amino acids: side-chain substituent effects. Int. J. Mass Spectrom. 2003; 227: 509

21. Frisch MJ, Trucks GW, Schlegel HB, Scuseria GE, Robb MA Cheeseman JR, Montgomery Jr JA, Vreven T, Kudin KN, Burant JC, Millam JM, Iyengar SS, Tomasi J, Barone V, Mennucci B, Cossi M, Scalmani G, Rega N, Petersson GA, Nakatsuji $\mathrm{H}$, Hada $\mathrm{M}$, Ehara $\mathrm{M}$, Toyota $\mathrm{K}$, Fukuda R, Hasegawa J, Ishida M, Nakajima T, Honda Y, Kitao O, Nakai H, Klene M, Li X, Knox JE, Hratchian HP, Cross JB, Adamo C, Jaramillo J, Gomperts R, Stratmann RE, Yazyev O, Austin AJ, Cammi R, Pomelli C, Ochterski JW, Ayala PY, Morokuma K, Voth GA, Salvador P, Dannenberg JJ, Zakrzewski VG, Dapprich S, Daniels AD, Strain MC, Farkas O, Malick DK, Rabuck AD, Raghavachari K, Foresman JB, Ortiz JV, Cui Q, Baboul AG, Clifford S, Cioslowski J, Stefanov BB, Liu G, Liashenko A, Piskorz P, Komaromi I, Martin RL， Fox DJ，Keith T, Al-Laham MA, Peng CY, Nanayakkara A, Challacombe M, Gill PMW, Johnson B, Chen W, Wong MW, Gonzalez C, Pople JA. Gaussian 03, Revision B.05, Gaussian: Pittsburgh, PA, 2003.

22. Becke AD. Density-functional thermochemistry. III. The role of exact exchange. J. Chem. Phys. 1993; 98: 5648.

23. Lee C, Yang W, Parr RG. Development of the Colle-Salvetti correlation-energy formula into a functional of the electron density. Phys. Rev. B 1988; 37: 785. 